\title{
Pobres meninas "ricas" com a gravidez
}

\author{
Maria Simone Vione Schwengber ${ }^{1}$
}

Resumo: Este artigo analisa a experiência [da gravidez] em adolescentes em situações de pobreza. Das análises, salta aos olhos que para as adolescentes o acontecimento da gravidez como uma busca de afirmação da própria existência no mundo (busca do próprio espaço), pois as adolescentes imaginam que a gravidez terá o condão de lhes proporcionar liberdade e autonomia, bem como de suprimir a carência por serem mais cuidadas (e respeitadas) pelos Outros, pelo serviço de saúde, em particular, pelo companheiro que, em geral, é mais velho (perspectiva de um "porto seguro" imediato). Assim, embora almejem romper com a tradição de sua família, acabam por intensificar a história familiar, reforçando a tradição do mito do amor materno e da equação das identidades mulher = esposa, mulher = mãe, em vez de desafiá-lo.

Palavras-chave: Gravidez; Adolescência; Maternidade; Pobreza.

\begin{abstract}
This paper analyzes the pregnancy experience of adolescents living in poverty. The analyses have evidenced that these girls regard their pregnancies as an affirmation of their own existence in the world (a search for their own place), as they imagine that pregnancy will be the magic wand that will provide them with freedom and autonomy, and will meet their need for being cherished (and respected) by the Others, by the health service and, particularly, by their partners, who are usually older than them (perspective of an immediate "safe harbor"). Hence, although the adolescents want to break with their family tradition, they end up intensifying their family history by strengthening both the myth of mother love and the identity equations: woman = wife, woman = mother, instead of defying them.
\end{abstract}

Keywords: Adolescent; Pregnancy; Motherhood; Schooling.

Resumén: Cet article analyse l'experience de la grossesse chez des adolescentes en situation de pauvreté. Des analyses, sautent aux yeux que, pour les adolescentes, l'événement de la grossesse c'est comme une recherche d'affirmation de la propre existence dans le monde (recherche de son propre space), étant donné qu'elles imaginent que la grossesse sera la "baguette magique" que leur fournira liberté et autonomie et va remplir ses carences d' avoir plus de soins (et être respectés) par les Autres, par les services de santé et, en particulier, par son compagnon, qui en générale est plus âgé (perspective d'un "port d'encrage" imédiat). Ainsi, malgré le désir de rompre avec la tradition de sa famille, les adolescentes finissent par intensifier l'histoire familialle, reforçant le mythe de l'amour maternel et l'équation des identités femme $=$ épouse, femme $=$ mère, au lieu de les défier.

Palabras clave: Mots clés; Adolescente; Grossesse; Maternité; Scolarisation.

\section{INTRODUÇÃO}

Esta pesquisa analisa a ocorrência de gravidez em adolescentes do Município de Ijuí-RS, buscando compreender, a partir de biografias - trajetórias afetivo-sexuais, familiares, educacionais - as experiências de adolescentes envolvidas com gravidez e com a maternagem precoces. Para tanto, partimos do seguinte questionamento: quais os sentidos e significados da experiência [gravidez] para as adolescentes?

1 Professora do Mestrado e do Doutorado em Educação nas Ciências da Universidade Regional do Noroeste do Estado do Rio Grande do Sul - Unijuí. Participante do Grupo de Estudos de Educação e Relações de Gênero (Geerge), vinculado ao PPG-EDU da UFRGS e do grupo Paidotribas da Unijuí. 
Esta pesquisa selecionou adolescentes grávidas, cadastradas na Secretaria de Ação Social de Ijuí - RS, uma vez que essa mantém Programas Sócio-Educativos Familiares (ASEF), mais especificamente com o CAAMI - Centro de Atendimento aos Adolescentes do Município de Ijuí-RS ${ }^{2}$, que é um ambulatório ${ }^{3}$ da Secretaria Municipal da Saúde de Ijuí-RS, específico para o atendimento a adolescentes na faixa etária dos 12 aos 18 anos.

\section{PROBLEMATIZAÇÃO DO OBJETO DE PESQUISA}

No Brasil, existe uma grande heterogeneidade nas trajetórias juvenis ${ }^{4}$, particularmente quanto aos modos de vivenciar a juventude e, inclusive, a gravidez. Brandão (2006) observa que, entre os grupos sociais mais favorecidos, há certo prolongamento da juventude, com o aumento do tempo de estudo, a aquisição tardia de autonomia econômica/material e, inclusive, níveis menores de gravidez na adolescência. Já nas classes populares, como destaca Heilborn (2003), a juventude tende a ser mais breve, com interrupções precoces nos estudos, pela inserção (ainda que precária) no mercado de trabalho e por acontecimentos como a gravidez.

Começamos perguntando: por que hoje a gravidez de uma adolescente/jovem é vista como um problema? Podemos destacar que na contemporaneidade ocorreram mudanças sociais profundas nos modos de vida das mulheres e das adolescentes. Sabemos que no limiar da modernidade, cuja expectativa de vida girava em torno dos 30 anos, registravam-se contratos de casamentos entre casais, em que a conjugue feminina encontrava-se ainda na faixa etária entre 13 e 14 anos. Nessa época em que a expectativa de vida era curta, a reprodução da espécie acontecia, portanto, nesse curto espaço de vida. Nas sociedades dessa época, as mulheres iniciavam sua vida sexual, muitas vezes, até mesmo antes da menarca, e os homens tão logo que despertassem os “instintos" sexuais e a capacidade de fecundar, como afirma Costa (1998).

Já na segunda década do século XX, na sociedade contemporânea brasileira, alteraram-se as idades das gestantes e os padrões de reprodução da população feminina. Os integrantes do grupo etário dos 25 aos 40 anos passam a ser os maiores responsáveis pelas taxas de reprodução humana, mostrando que ocorreu um “envelhecimento”, em relação à Modernidade, na estrutura etária responsável pela reprodução no Brasil.

\footnotetext{
2 Ijuí é um município brasileiro de pequeno porte, localizado no interior do Estado do Rio Grande do Sul, com uma população de aproximadamente 78.990 habitantes, com uma taxa de populacional urbana de $87 \%$ e uma rural de $13 \%$. Ijuí é uma cidade que se destaca regionalmente como prestadora de serviços, sobretudo, na área da Saúde e Educação, por atender mais de 48 (quarenta e oito municípios). Ijuí é conhecida como terra das culturas diversificadas, pela mistura de várias etnias que a compõem. Ijuí apresenta conforme SEPLAN - Secretaria de Planejamento e Coordenação, (2007), taxa de analfabetismo: de 4,78 \% e tem uma expectativa de vida ao nascer (2000): de 69,14 anos, Coeficiente de mortalidade infantil (2008): 11,43 por mil nascidos vivos PIB (2002).

3 O CAAMI presta atendimentos específicos aos adolescentes nas áreas de: medicina (clínica de adolescentes, ginecologia e obstetrícia e urologia), psicologia, nutrição, enfermagem, pedagogia.

4 O emprego da expressão "adolescentes e jovens", ao longo deste artigo, tem a ver com uma opção teórica feminista que assumo, baseada em Louro (1999) e Meyer (2003), de pensar a pluralidade de sujeitos femininos a partir de múltiplos atravessamentos, tais como: raça, geração, etnia, classe, religião. No Ocidente, nem todas as meninas e mulheres têm iguais possibilidades de escolha nas suas vidas individuais, devido a diferentes situações sociais.
} 
No Brasil, observa-se uma queda na taxa de fecundidade a partir da segunda metade do século XX. No século XXI a média de fecundidade assim se configurava: em 1940, cada mulher brasileira tinha em média 6,16 filhos; em 1950, 6,21; em 1960, 6,28; em 1970, 5,76; em 1980, 4,35; em 1990, 2,9; em 2005, 2,8, conforme Berquó (2007).

Medeiros (2006) chama a atenção para o fato de que a taxa de fecundidade caiu na classe médiaalta, bem como nas classes menos favorecidas ${ }^{5}$, que se aproximam da média geral. De acordo com a pesquisa do IBGE (2007) os brasileiros têm em média 2,8 filhos. Na população com renda inferior a 2 salários mínimos, essa média chega a 3,1 filhos.

Na segunda década do século XX, emergiram políticas mais firmes em relação à quantidade de filhos/as, e o incentivo à redução do número de filhos/as consolidou-se como posição de efeitos visíveis na cultura brasileira, principalmente depois da década de 80. Para Corrêa (2000), essa redução se deu por vários fatores ${ }^{6}$, tais como: elevado uso da esterilização feminina, da pílula e de outros contraceptivos; expansão da escolaridade feminina, aumento do número e permanência de mulheres no mercado de trabalho; expansão do emprego no setor terciário; transformações dos valores relativos ao lugar social das mulheres.

Desse modo, observa-se uma transformação social que mudou a perspectiva das mulheres em relação à maternidade, antes mais vinculadas à maternidade e ao lar; hoje passaram a se vincular também aos processos de escolarização e profissionalização. De modo que a maternidade, sobretudo para a adolescente de hoje, passa a ser incompatível com as demandas sociais da "nova" mulher, para a qual a se apresenta a possibilidade de dedicação aos estudos e à profissionalização para garantir um futuro tranquilo (como alguém que responda minimante por si). As expectativas sociais diante da juventude/adolescência se modificam social e historicamente: em um dado momento, a gravidez aos 14 e 15 anos é tida por aceitável e "natural", ao passo que em outro é considerada inaceitável ou mesmo problemática diante das expectativas e desafios que são vislumbrados para as mulheres e as adolescentes hoje, por exemplo. O padrão de reprodução das mulheres adultas tem se alterado muito nas sociedades ocidentais contemporâneas, pelo redimensionamento das novas formas educativas, pelas transformações nas relações de gênero e entre gerações. Porém, houve aumento na proporção de adolescentes que engravidam e que concluem a gestação. Entre os anos de 1996 e 2006, a média entre as meninas grávidas de 15 a 17 anos subiu de 6,9\% para 7,6\%. Uma (1) em cada 5 adolescentes (10 a 20 anos) já é mãe ou está grávida do $1^{\circ}$ filho no Brasil. Cerca de 1,1 milhão de adolescentes brasileiras engravidam por ano, e esse número continua crescendo.

5 Para Marcelo Medeiros (sociólogo pesquisador do IPEA), pensar que a miséria no Brasil decorre do tamanho excessivo das famílias é uma maneira confortável de se transferir para os pobres a responsabilidade por sua pobreza. O discurso de justificar a pobreza pela alta natalidade é frágil, não enfrenta o que realmente é grave e o que está por trás da pobreza e de outros problemas no país: a desigualdade social. Para o autor, estudos também do IPEA "sobre as mudanças ocorridas na composição das famílias brasileiras ao longo dos últimos 30 anos indicam que, hoje, a proporção de domicílios que têm mais de três filhos com idade inferior a dez anos não chega a 3\% do total de domicílios brasileiros. Famílias enormes estão cada vez mais raras, fazendo com que medidas controlistas sequer possam ser aplicadas a grandes parcelas da população" (MEDEIROS, 2006, p. 1).

6 A partir da década de 1980, tornou-se claro que a fecundidade no Brasil estava diminuindo bastante; hoje, a média brasileira não é muito maior do que a observada em países bem mais ricos (IPEA - Instituto de Pesquisa Econômica Aplicada). 
Na virada do milênio, no Brasil, as mulheres jovens, sobretudo as pobres, continuam a engravidar nessa proporção. Esse dado é importante porque remete a um problema cada vez mais frequente no mundo, inclusive no Brasil, em que pode se dizer que há quase uma "epidemia" de gravidez na adolescência. Em apenas 10 anos, de 1995 a 2010, praticamente dobrou o número de jovens que engravidam entre 12 e 20 anos, cerca de dois terços das grávidas brasileiras têm menos de 20 anos (Cf. IBGE, 2008), o equivalente a 70\% do total de gestantes do país (Cf. IBGE, 2013).

A sociedade contemporânea se modificou e as mulheres vislumbraram diferentes perspectivas de vida. No entanto, isso não impediu e não impede que a cada ano mais jovens pobres engravidem numa idade em que deveriam envolver-se com outras questões. Pesquisas como as de Heilborn (2003), Gontijo e Medeiros (2004), Schwengber (2007) mostram que não é a desinformação que leva à gravidez na adolescência. Estudo realizado em São Paulo, no Hospital de Clínicas (2008), mostra que $92 \%$ das adolescentes entrevistadas conheciam pelo menos um método contraceptivo. Dessas, apenas $25 \%$ planejaram a gestação, muitas abandonaram o método contraceptivo que usavam com intuito declarado de engravidar. É importante destacar que os métodos contraceptivos transformaram a maternidade em uma decisão a ser tomada voluntariamente. Para Marina (2008), as meninas de hoje, quando chegam à adolescência, são expostas, via meios de comunicação de massa, a uma cultura mais informativa, porém, ao mesmo tempo, mais sexualizada e apelativa. Então, parece que não é a desinformação que leva à gravidez na adolescência. Perguntamos: mas o que é então?

No passado atribuía-se a chamada explosão demográfica à ignorância dos pobres ou, pior, a definiam como uma espécie de perversidade, que fazia com que se reproduzissem como coelhas. O jeito era, como destaca Scliar (2008), fazê-los usar contraceptivos de qualquer maneira. Agora sabemos que esse acontecimento é mais complexo do que parece; e há nisso uma clara mensagem para os estudos feministas e para as políticas públicas, para os pais e as escolas. As adolescentes precisam ser ajudadas (corporal e psicologicamente) antes que optem pelo "pacto da gravidez", como as seguintes histórias, pelas quais justificamos a pesquisa em questão.

\section{O UNIVERSO INVESTIGADO}

Foi realizada uma pesquisa etnográfica (2006 a 2014) junto ao CAAMI (Centro de Atendimento aos Adolescentes do Município de Ijuí-RS) em que localizamos e conhecemos as histórias das adolescentes e de suas famílias referidas neste artigo. Isso foi possível porque uma das particularidades desse serviço em relação aos demais existentes no município de Ijuí - RS é o fato de dispensar atenção às adolescentes grávidas. O CAAMI presta atendimentos específicos às adolescentes nas áreas de: medicina (clínica de adolescentes, ginecologia e obstetrícia), psicologia, nutrição, enfermagem, pedagogia. Cabe lembrar que essas adolescentes são, ao mesmo tempo, herdeiras de uma posição contemporânea associada ao controle e à vigilância dos grupos populares e impregnado dos ideais de proteção à infância e de valorização e normalização da família.

A faixa etária das adolescentes grávidas situa-se entre 14 e 19 anos. A vida das meninas pesquisadas e das suas famílias é representada pela grave presença da violência e pela pobreza impostas, pois 
precisam sobreviver mensalmente com uma renda de menos de um salário mínimo (complementado pelo trabalho de biscate e do Programa Bolsa Família). Grande parte das famílias das adolescentes pesquisadas tem renda apenas para subsistência precária. Contingências como desemprego, emprego temporário, doenças, separações, famílias com relativa instabilidade financeira. A maioria das adolescentes pesquisadas deixou de estudar ainda no decorrer do Ensino Fundamental. A maioria delas diz ter um parceiro estável (o pai de seus filhos) e outras não possuem parceiro fixo. Com relação à idade do parceiro, a mesma varia de 19 a 34 anos, e algumas delas não sabem a idade do pai do filho. A religião preponderante das adolescentes é a protestante, em especial, pentecostal. Elas mencionam a televisão como um dos maiores veículos de entretenimento e informação.

\section{ORGANIZAÇÃO DOS DADOS}

Fizemos um estudo de inspiração etnográfica. Nesse, conduzimos entrevistas semiestruturadas com questionário aberto, com questões centrais que desencadeavam as conversas.

Após, os diários de campo e as entrevistas foram lidas, de muitos modos, e individualizadas, buscando-se identificar, de maneira singular, as ideias centrais de cada depoimento. Em seguida, fez-se a codificação dessas ideias que, segundo Louro (1997), é o processo pelo qual os dados são transformados e agregados em unidades, as quais permitirão uma descrição mais complexificada dos conteúdos (tema) das entrevistas. Fez-se então uma leitura transversal das entrevistas, separando-as por categorias temáticas que emergiram do discurso das entrevistadas, e inicialmente organizadas assim:

a) Modos como vivem e a relação que estabelecem com o acontecimento da gravidez na adolescência, bem como os impactos desse acontecimento nas suas trajetórias de vida.

Este estudo apoia-se na análise do discurso, na perspectiva de Foucault, tomando o campo textual das entrevistas, o depoimento (suas linguagens) como narrativas discursivas. Foucault (2004) sugere ainda que o/a pesquisador/a capte, de preferência, nas formações discursivas, aquilo que é dito e/ou o lugar que as pessoas assumem no discurso, a "posição de sujeito".

Trabalhamos arduamente com as próprias narrativas discursivas, deixando o discurso aparecer na "complexidade que lhe é peculiar, nos enunciados" as posições de sujeito. Para dar conta disso, Michel Foucault sugere que nossa primeira tarefa seja a de nos desprender do aprendizado dos/as pesquisadores/as que olham os discursos como conjunto de signos, como significantes que se referem a determinados significados e garimpar as "reais intenções" que estavam ocultas nos discursos. Trata-se, ao contrário, de trabalhar no interior do discurso, "estabelecer séries, distinguir o que é pertinente, descrever as relações, definir as unidades enunciativas" (SCHWENGBER, 2008, p. 57).

A análise do discurso, na perspectiva foucaultiana, compreende o discurso como um ato social e estuda as relações enunciativas que atravessam a linguagem, no sentido de que as palavras "não são apenas expressões que se dissolvem, mas elas têm o corpo e o peso da 
história" (LOURO, 1997, p. 140). ${ }^{7}$

A fim de situar a experiência de maternidade das adolescentes pesquisadas, a partir de histórias de vida, trouxemos neste artigo as biografias de Fabiana e Raquel.

\section{GRAVIDEZ NA ADOLESCÊNCIA: UM PACTO AO DESAMPARO}

Fátima Soares e Alair dos Santos, um jovem casal de Ijuí-RS, com 10 filhos: Clara (6 meses), Camila (1 ano), Rúbia ( 2 ano e 5 meses), Jaqueline (3 anos), Sabrina (5 anos), Juliana (7 anos), Juliano (9 anos), Ana Paula (12), Raquel (14 anos) grávida do primeiro filho e Fabiana, com 16 anos, já perdeu um filho e está também grávida. Fátima tem 33 anos, Alair 30, e estão prestes a ser avós. Fátima teve vários filhos de parceiros diferentes, muitos deles ausentes, de experiências conjugais instáveis e de curta duração.

A renda que sustenta os oito filhos (duas adolescentes que já saíram de casa) e os dois adultos vem do trabalho de Alair, que faz calçamento e recebe por semana cerca de $\mathrm{R} \$ 80,00$, mais $\mathrm{R} \$ 110,00$ que Fátima recebe do Bolsa Família; somados são R\$ 430,00 ao mês. Fátima tem apenas a $1^{\text {a }}$ série, e o fato de ter que cuidar dos filhos justifica seu impedimento para trabalhar. Pergunto: quantos filhos ainda terá a própria Fátima, que diz não ter planejado ter tantos filhos? E quantos filhos mais terão Raquel e Fabiana ${ }^{8}$ (filhas de Fátima)? , uma vez que as duas já estão grávidas, conforme respectivos depoimentos expostos no texto.

Fátima, quando questionada sobre os meios de prevenir a gravidez, conta que a forma que melhor conhece é o uso do anticoncepcional, mas que "alguma coisa deu errado". Disse ela: "às vezes eu tomava, outras vezes eu esquecia". Tal esquecimento resultou em dez filhos para criar, alimentar, vestir e educar. Fátima foi orientada, várias vezes, pela assistente social e pelas agentes de saúde da Secretaria Municipal de Saúde, porém essas orientações pouco efeitos produziram em Fátima9 Perguntamos que efeitos produzirão em Fabiana e Raquel, que já estão grávidas?

Fabiana e Raquel afirmam que ficaram grávidas durante uma das primeiras relações afetivas com um companheiro mais velho, e agora cada uma divide uma outra pequena casa com seu companheiro. Mesmo que essa seja ainda um "puxado" (prolongamento) como dizem, popularmente, no pátio da casa dos pais de seu companheiro.

É interessante pensar nos depoimentos de Fabiana e Raquel, quando dizem: "Engravidar, para mim, pelo menos foi bom (...), foi uma forma de ir morar com o meu companheiro e sair daquela casa, pois lá eu precisava dividir tudo. (...) Eu já “tava” grande demais. Engravidei porque pensava

7 A recente iniciativa sobre o uso (politicamente correto) do artigo masculino o e do feminino a significam, segundo Louro (1997), uma crescente tomada de consciência pelas pessoas de que as palavras fazem coisas e sugerem certo tipo de efeitos que regulam e vigiam a ordem social.

8 A atividade sexual entre os jovens vem ganhando cada vez mais espaço nos debates acerca da ocupação demográfica e nas políticas públicas, por estar intimamente ligada ao aumento relativo da reprodução entre os jovens. Esse comportamento destaca-se por contrariar as tendências verificadas para os demais grupos etários, visto que o Brasil está consolidando sua transição demográfica, embora esse aumento relativo da fecundidade tenha seu maior peso na adolescência.

9 Apenas depois do oitavo filho é que Fátima começou a tomar anticoncepcionais injetáveis. 
que tinha chegado o momento de construir a minha família". (Fabiana, 16 anos). Já Raquel diz: "Eu engravidei e sai da escola (...) eu era a maior da turma, meu corpo "tava" grande demais, eu tinha vergonha de continuar lá, (...) também porque sabia menos que as crianças pequenas (...) quando eu engravidei não tinha e não via nenhuma possibilidade de emprego para mim”. (Raquel, 14 anos).

Ouvindo, inicialmente, a história de Fabiana e Raquel, perguntamos: quais as ancoragens de ligação (vínculos) que elas têm com o mundo vivido? Que preparo o processo de escolarização produziu nelas em relação à perspectiva de trabalho e de (sobre)vivência neste mundo? Recém saídas da infância, as adolescentes Fabiana e Raquel sobrevivem na linha que podemos dizer que fica entre a pobreza e a miséria. Parece que há no mundo contemporâneo, por um lado, um desencontro entre as exigências (demandas) de estudo e de trabalho com que essas jovens deparam-se; por outro, a dificuldade que existe, atualmente, para essas jovens encontrarem um lugar no mundo dos adultos. Novas configurações familiares, sistema educacional frágil, restrições no mercado de trabalho e acesso restrito aos bens de consumo (tão valorizados na sociedade contemporânea) são condições que as empurram a que perspectivas?

Notamos, por exemplo, as dificuldades na escrita de Fabiana e Raquel, quando solicitamos que fizessem um exercício simples de associar palavras ao enunciado mãe.

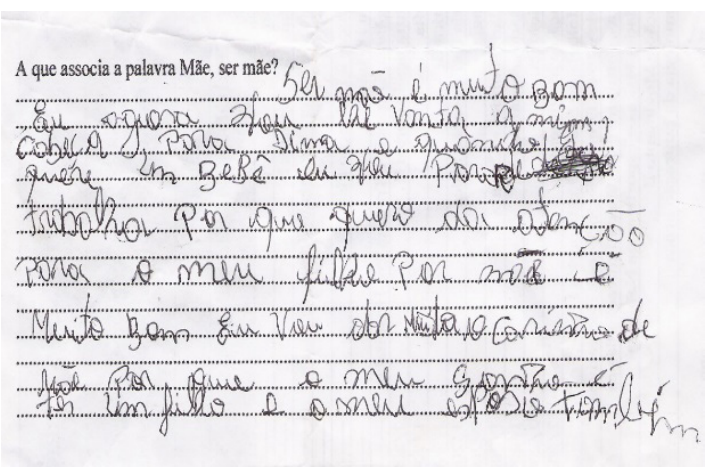

Fig. 1 - Depoimento da Raquel

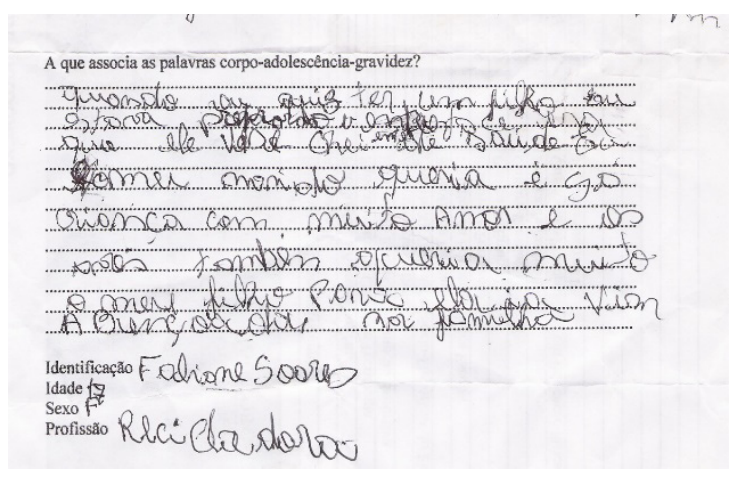

Fig. 2 - Depoimento da Fabiana

As irmãs, quando fizeram esse exercício, cursavam as Séries Finais do Ensino Fundamental, porém pouco sabem ler e escrever e apresentam dificuldades primárias de compreensão de ordem simples, como as do enunciado acima. As meninas ainda diziam-nos: "nós não sabíamos quase nada, mas mesmo assim passávamos de ano, nós tava-mos na escola né, mas não tava-mos”.

Pode-se dizer que trajetória escolar de Fabiana e Raquel reflete assim o típico "abandono escolar" (ou seria a "exclusão")? Cerca de $68 \%$ da população, representada por 83,4 milhões de brasileiros, com idade entre 15 e 64 anos, são analfabetos funcionais, ou seja, que só compreendem frases curtas, com informações explícitas (como textos publicitários) e identificam números em contextos específicos, como $\operatorname{preços}^{10}$ (INAF, 20007, p.17). A Fabiana e a Raquel mostram que, apesar de frequentar a escola

10 Os dados são do Indicador de Alfabetismo Funcional (INAF), do Instituto da divisão social do Ibope. 
até os Anos Finais do Ensino Fundamental, estão distantes da classificação de alfabetizadas ${ }^{11}$.

Observando as dificuldades nos excertos dos registros das figuras 1 e 2, escritos acima, perguntamos: foram as meninas que abandonaram a escola, ou foi a escola que as abandonou? Sabemos que maus resultados escolares levam a consequentes desinteresses pela escola. A escola, por sua vez, representa para essas meninas locus de experiências negativas e de relacionamentos difíceis. Com isso, por exemplo, a Raquel claramente afirma "se está na escola, mas ao mesmo tempo se está fora dela".

O depoimento de Raquel chama-nos a atenção quando diz: “(...) eu era a maior da turma, meu corpo "tava" grande demais eu tinha vergonha de continuar lá na escola (...) eu era a mais grande da turma e ainda sabia pouco". (14 anos).

A Raquel nos coloca face-a-face com uma situação que suscita uma séria reflexão, quando diz: “(...) um corpo grande demais para estar na escola (...)", um corpo que, segundo ela, não serve para escola; mas, que serve para a maternidade, pode-se dizer meu corpo, [meu útero], meu capital. O corpo marca os limites entre o "dentro e fora" (da escola), serve de encontro entre o mundo externo e interno. Soares (2001) chama-nos a atenção para o quanto esse julgamento do corpo (de ser grande demais) na adolescência se torna crucial, pois uma grande necessidade de valorização e aceitação há nessa fase. Trata-se, talvez, aqui de pensar o uso social dos corpos que essas adolescentes fazem, via gravidez. Seus corpos como veículos de mobilidade social.

\section{USO SOCIAL DOS CORPOS}

Como diz Raquel: "Eu não estou só [mente], eu tenho meu corpo". É a partir do seu corpo que Raquel, faz escolhas (?), toma atitudes. Com seu corpo, Raquel constrói laços de aliança e de afeto, mas também de antagonismo, de discriminação e de exclusão, quando justifica porque saiu da escola. A existência de Raquel, traduzida no seu corpo, demarca o seu "estar-no-mundo", como destaca Merleau-Ponty (1995). Para o autor, os corpos:

Nunca estão fora da história e a história nunca está livre da presença dos corpos e de seus efeitos. As dicotomias subjacentes ao reducionismo agora têm que ser substituídas por uma explicação mais adequada e complexa das relações sociais nas quais as incorporações e interações ocorrem (MERLEAUPONTY, 1995, p. 87).

A condição juvenil e os significados dessa nova imagem social [corpo adolescente] formam um conteúdo de argumentação que podemos destacar como ambígua, visto que são corpos de meninas “aquelas que já não são crianças, mas ainda não são adultas”. Rodrigues (1999) ressalta:

11 Para a diretora-executiva do Instituto Paulo Montenegro, Ana Lúcia Lima, a situação é reflexo da universalização da educação básica (escola para todos), que não prima pela qualidade. Dividindo o ensino público entre "antes e depois", ela observa que "a escola para poucos recebia estudantes mais bem preparados" As crianças de hoje são filhas de pais analfabetos ou com pouco grau de instrução. $\mathrm{O}$ amplo acesso é positivo, mas a escola não se preparou para receber esses alunos" explica ela. A posse necessária de capital social, cultural e econômico, tem sido, desde sempre, o desafio para famílias negras em suas trajetórias pessoais e coletivas. 
(...) o que chamamos de puberdade e de adolescência é extremamente difícil de ser fixada cronologicamente e os seus sinais parecem variar com os diferentes costumes, hábitos alimentares, condições climáticas, profissões, hereditariedade - entre outros fatores - tanto para o sexo feminino, como para os membros do sexo masculino: aparência da barba, secreção de múcus, emissão de esperma, crescimento, aparecimento de regras, crescimento do seio e da bacia - não podem ser datados consensualmente. (...) o que se espera, em cada cultura, dos indivíduos, durante as diferentes fases da vida, não são, absolutamente, as mesmas coisas, atividades ou responsabilidade entre nós, por exemplo, a idade em que permite aos jovens o casamento não coincide com a sua puberdade fisiológica, ao passo que em outras culturas a puberdade se celebra com o casamento e em algumas o casamento antecede a puberdade (RODRIGUES, 1999, p. 82).

O termo adolescência ${ }^{12}$ vem do latim adulescens ou adolescens, que significa crescer (LAROUSSE, 2008). Durante a adolescência ocorrem modificações corporais suficientes para desencadear crises e afirmações de identidade(s). Existe nesta fase uma forma peculiar de mudanças corporais que enfatiza as diferenças em relação à criança e, ao mesmo tempo, demarca a semelhança ao adulto como seus iguais. A iniciação sexual é considerada um dos importantes ritos dessa passagem. A sexualidade se destaca como campo em que muitas vezes os/as adolescentes encontram o reconhecimento social, pela e na emergência da potência sexual de seus corpos (sua sexualidade); como vimos acontecer, segundo os respectivos depoimentos, com Fabiana e Raquel e muitas outras meninas da pesquisa, recém saídas da infância.

O corpo com a respectiva sexualidade é, para Raquel, o seu principal capital, ou uma das suas importantes riquezas. Atributos de seus corpos (potência reprodutiva) desempenham um papel significativo como o de inseri-las socialmente. Goldenberg (2007) observa que no Brasil, um país em que as pessoas, de um modo geral, têm poucos investimentos em outros capitais - como educacional e cultural - o corpo acaba se tornando importante capital econômico e social. Para a autora há supervalorização dos corpos jovens, hoje, nos relacionamentos e comportamentos afetivo-sexuais, de modo que o corpo se tornou como um "capital talvez o mais importante desta geração e época" (GOLDENBERG, 2007, p. 18). Ainda para Goldenberg (2007), a atração afetiva da maioria dos casais no Brasil começa, basicamente, pelos apelos da atração corporal (sexual). Para a autora o corpo é uma herança do processo de colonização do País ${ }^{13}$.

Parece que, para se defender, essas jovens lançam mão então de seus corpos (sua sexualidade) como uma alternativa que conduz à ocupação de um lugar no mundo social, ocupar um lugar no espaço. Corpo feminino, corpo reprodutor, "a maternidade que se desdobra e a faz integrar no mundo do social, afirmando a representação da identidade mulher = mãe” (MEYER, 2006, p. 12).

12 O conceito de adolescência tem uma origem bastante recente na história social do Ocidente, e seu sentido atual só foi, definitivamente consolidado no final do século XIX situado enquanto um processo relativo a um período particular na vida dos indivíduos, entre a infância e a idade adulta, como destaca Ariès (1985). Assim, a adolescência é um conceito construído historicamente na Modernidade, que adquire vários desdobramentos até o momento atual.

13 Miriam Goldenberg (2007, p. 22) recorre a Gilberto Freyre que, no clássico Casa grande \& senzala, analisou "a importância do corpo desde o início da colonização brasileira como constituinte da identidade brasileira. Nossa colonização se deu pelo encontro dos portugueses (exemplo Peri) e as índias (Iracema), que apreciaram a valorização dos corpos. Depois vieram os corpos dos escravos e escravas, que ocuparam espaços enormes na casa grande e povoaram o país." 
"Eu engravidei!", afirma Raquel. Esta condição, como diz Swain (2008), afirma uma essência do feminino ainda aliada aos corpos, ao biológico, uma definição identitária fundada na procriação, no casamento, na sedução. Para a autora, isto "mostra claramente a divisão do trabalho social, em que o corpo é para as mulheres, o eixo de sua existência social" (SWAIN, 2007, p. 286).

Assim, pode-se dizer que tanto a gravidez de Raquel quanto a de Fabiana não é um acidente, não é imprevista, indesejada, indevida, inoportuna, nem precoce. Parece que essas duas meninas efetivam, com a sua gravidez, o amparo, a posição de mulher-mãe; o filho, a família, dá a elas uma vinculação social mais segura. Nesse contexto, as adolescentes buscam auto afirmar-se nesse mundo excludente, através de uma gravidez que, dependendo do ângulo que for observado, parece precoce.

Para Kolyniak (2004), é na adolescência, fase de estruturação das identidades, que o aprendizado necessita de testemunho e de modelos. Não se aprende pelo simples modelo de transferência, mas numa relação de confiança. Para Aberastury (2004), os dispositivos dos laços societários compartilhados - os rituais de passagem ${ }^{14}$ - cumprem funções, ao ajudarem o/a adolescente a fazer essas passagens. A complexidade do mundo contemporâneo acirrou a perda dos muitos rituais exigindo dos adolescentes e jovens um amadurecimento mais individualizado e, por isso, mais complexo. A adolescência emerge hoje nesse caldo de um contexto sociocultural individualista, em que a cada indivíduo adolescente ou jovem é delegada a responsabilidade de administrar seu próprio destino, encontrar o seu lugar no social da maneira que lhe for preferível ou possível.

A condição de mãe talvez signifique para essas adolescentes a necessidade de se reinventarem. Uma vez que não encontraram lugar para si, com [a gravidez] as meninas abrem para possibilidade de criar - uma obra, um filho. Inventam-se muito cedo como mulher=mãe, a partir do rígido e limitado lugar de menina "pobre” (MEYER, 2006).

Para Fonseca (2004), a gravidez pode significar, para muitas, uma aliança econômica e política: as meninas "ofertam", por não terem bens a trocar, resta-lhes a única moeda que a elas têm a oferecer: corpo, sexo [a reprodução]. Fonseca, analisando o número de filhos de casais em extrema pobreza no Brasil, afirma:

Tanto para as mulheres como para os homens, ser mãe e ser pai é uma fonte de prestígio. A família atingida pelo desemprego, mesmo de longa duração, não renuncia a fecundidade. Não somente para as mulheres, mas também para os homens, privados da legitimação pelo trabalho, a fecundidade constitui uma valorização narcísea eletiva, assim como um modo de defesa contra a falta, a abundância dos corpos substituindo a dos bens (SCHWARTZ, 1993 apud FONSECA, 2004, p. 142).

14 Exemplos de rituais de passagem: formaturas, lugares de ser calouros e veteranos em duas ou três etapas da trajetória escolar, passar no vestibular, os novos documentos (título de eleitor, carteira de motorista, alistamento), ato de votar, comemoração dos aniversários de 15 e 18 anos, a compra do primeiro sutiã, a primeira camisinha, a primeira relação sexual, as primeiras viagens sozinhos e ou em grupo; o ingresso no mercado de trabalho, tudo isso pode ser, mais ou menos ritualizado nos contextos familiares e escolares. O fato é que não existe uma referência clara a respeito do marco temporal de passagem. E contextos se diferenciam de acordo com a classe social e das vivências possíveis dentro de cada segmento de classe. Para alguns autores, como Sant'Anna (2004), o caso da tatuagem, dos piercings, nos dias de hoje, podem ser tomados como rituais, pois marcam e diferenciam os corpos. Como também fazem parte dos anti-rituais, o tabaco e a ingestão de álcool. Muitos jovens vão buscar apoio em seu próprio grupo e nos heróis de sua geração (roqueiros, artistas e escritores). 
É possível localizar, nos depoimentos de Fabiana e Raquel, a perspectiva da vivência de severas privações sociais e culturais e, então, é que a maternidade lhes atribui um papel de reconhecimento social, o de mãe. É possível identificar no discurso das meninas uma associação vantajosa da posição de estar grávida. Tal como o depoimento de Raquel: "Eu adorei essa gravidez, a gente aprende a gostar mais da gente e do filho, por saber que a gente é gente, agora eu vou fazer a minha carteira de identidade." (14 anos).

Nos seus depoimentos inscrevem-se fios discursivos que reforçam representações em que a maternidade para as adolescentes as coloca na posição de "cuidadas". E assim buscam uma afirmação identitária de mulher=mãe, como participantes do jogo social (MEYER, 2006). Como Fabiana disse: "agora eu tenho "cartão da gestante e tenho marido." Perguntamos: marido ou cuidador?

Para Marina (2008), a sociedade, com vínculos afetivos frágeis, que emergiu no século XX, introduziu profundas variações no modo de considerar a maternidade. Para a autora, muitas mulheres, incapazes de viver sem algum tipo de "ancoragem, de ligação, procuram no filho uma vinculação mais segura do que no parceiro" (MARINA, 2008, p. 109). Raquel afirma abertamente: "tive meu filho também por medo do vazio que se abria de mim, por medo do meu futuro incerto." O depoimento de Raquel lembra que “(...) em um mundo individualista e hostil, a família e os filhos aparecem como último reduto de segurança” (MARINA, 2008, p. 109). E ainda em mundo de uniões sem compromisso, "anseia-se por uma relação comprometida e indissolúvel, como a da maternidade, diante da insegurança afetiva, é vista nela uma possibilidade de relação amorosa clara, segura e inevitável, quase automática” (MARINA, 2008, p. 110).

A partir da sociedade moderna valoriza-se a posição de "mãe". A figura da mãe como a imagem da "verdadeira mulher" (MEYER, 2006) é uma representação forte, construída na cultura cotidiana ocidental, tecida por uma densa rede discursiva que entrelaça memória da tradição e de autoridades diversas. A concretização da reprodução [a gravidez] e a maternidade configuram-se ainda na cultura ocidental como a concretização do corpo da "verdadeira mulher" (SWAIN, 2007).

Ser mãe é uma experiência que parece justificar a existência de quase todas as mulheres. Para Swain (2007), apesar das transformações ocorridas com algumas normas sociais (de maneira pontual e localizada), o casamento e a maternidade "povoam os sonhos e o imaginário das mulheres que se consideram completas apenas se forem mães e esposas" (SWAIN, 2007, p. 219).

A gravidez/maternidade na adolescência envolve dimensões complexas remetendo, no caso de Fabiana e Raquel, à reafirmação de projetos de mobilidade social em nome do estabelecimento do laço mãe-criança, menina = mãe e mulher. As adolescentes, em suas narrativas da gravidez, referem-se como parte de um projeto de vida de constituição da família, uma espécie de passaporte para entrar na vida adulta e ter reconhecimento social.

Da análise desprende-se que a gravidez estimula as adolescentes a ser alguém na vida, como diz Raquel: "agora não sou uma pé-de-chinelo; agora sou uma mulher rica, tenho meu filho; agora sou mãe, tenho mais responsabilidade; mudou muita coisa na minha vida, sou mais respeitada". 
Ampliar e facilitar o acesso aos métodos anticoncepcionais entre as comunidades carentes é importante, mas parece que essa ação sozinha não é uma resposta satisfatória. A solução exige que se associem outras políticas de saúde e educacionais. Inclusive a inclusão de histórias como as de Fabiana e Raquel. Perguntamos: para que serve a história das mulheres? Para reconhecê-las como ser e, até mesmo, para qualificar as políticas públicas e educacionais voltadas às mulheres (adolescentes).

\section{Referências}

ABERASTURY,Arminda. Adolescência normal.Um enfoque psicanalítico. Porto Alegre: Artes Médicas, 2004. BRANDÃO, Elaine Reis. Gravidez na adolescência nas camadas médias: um olhar alternativo. In: ALMEIDA, Maria Isabel Mendes; EUGENIO, Fernanda. (Orgs.). Culturas Jovens: novos mapas do afeto. Rio de Janeiro: Jorge Zahar Ed., 2006. p. 79-91.

COSTA, Jurandir Freire. Ordem médica e norma familiar. Rio de Janeiro: Graal, 1998.

FOUCAULT, Michel. A ética do cuidado de si como prática da liberdade. In: Ética sexualidade, política. Ditos e escritos. Rio de Janeiro: Forense: 2004. Universitária, vol. V.

FONSECA, Claudia; TERTO, Veriano; ALVES, Calef, (Orgs.). Antropologia, diversidade e direitos humanos: diálogos interdisciplinares. Porto Alegre: UFRGS, 2004.

GOLDENBERG, Mirian (Org.). O corpo como capital: estudos sobre gênero, sexualidade e moda na cultura brasileira. Barueri, SP: Estação das Letras e Cores, 2007.

GONTIJO, Daniela Tavares; MEDEIROS, Marcelo. Gravidez/maternidade e adolescentes em situação de risco social e pessoal: algumas considerações. Revista Eletrônica de Enfermagem. V. 06, n. 03, p. 394-399, 2004. Disponível em <http://www.fen.ufg.br> Acesso em 20 mar. 2008.

HEILBORN, Maria Luíza. Estranha no ninho: geração, tempo e sexualidade. In: VELHO, Gilberto \& KUSCHNIR, Karina. (Orgs.). Pesquisa urbana: desafios do trabalho antropológico. Rio de Janeiro: Zahar, 2003.

INSTITUTO BRASILEIRO DE GEOGRAFIA E ESTATÍSTICA - IBGE. Séries estatísticas retrospectivas/Fundação Instituto Brasileiro de Geografia e Estatística. Rio de Janeiro: IBGE, 2008 .

KOLYNIAK FILHO, Carol. Educação física: uma introdução. São Paulo: EDUC, 2004.

LAROUSSE. Dicionário eletrônico. São Paulo: Ediouro: Cd: 2004

LOURO, Guacira L. Gênero, sexualidade e educação: uma perspectiva pós-estruturalista. Petrópolis: Vozes, 1997.

MARINA, José Antonio. O quebra-cabeça da sexualidade. Rio de Janeiro: Guarda-chuva, 2008.

MEDEIROS, Marcelo. Planejamento familiar: os filhos dos pobres. <http:/www.cfemea.org.br/ temasedados/detalhes.asp?IDTemasDados=83> Acesso em out. 2006.

MEYER, Dagmar. A politização contemporânea da modernidade. Gênero: núcleo transdisciplinar de estudos de gênero - NUTEG, Niterói, v. 6, n. 1, 2006.

PONTY, Merleau. Fundamentos de fenomenologia. São Paulo. Editora Moraes. 1995.

RODRIGUES, José Carlos. O corpo na história. Rio de Janeiro: Editora Fiocruz, 1999. 
SCLIAR, Moacyr. Fazendo o próprio caminho. ZERO HORA. 03 de agosto, de 2008 | N$^{\circ} 15682$. SWAIN, Tania. Maternidade e feminismo, diálogos interdisciplinares. Florianópolis: Editora das Mulheres, 2007.

SCHWENGBER, Maria Simone Vione. Imagens de corpo imposta à infância nas pedagogias culturais em circulação. In: XII Congresso Brasileiro de Ciências do Esporte, 2001, Caxambu, 2001.

1, p. $1,2008$. . A mãe forte associada à mãe esportiva. Lecturas Educación Física y Deportes, v. 